\title{
A Single Dose-Escalation Study to Evaluate the Safety and Pharmacokinetics of Orally Administered Des-Aspartate Angiotensin I in Healthy Subjects
}

\author{
Ko-Onn Lee ${ }^{1} \cdot$ Chin-Meng Khoo ${ }^{1} \cdot$ Balram Chowbay $^{2,3,4} \cdot$ Yiong-Huak Chan $^{5}$ • \\ Meng-Kwoon $\operatorname{Sim}^{6}$
}

Published online: 28 September 2016

(c) The Author(s) 2016. This article is published with open access at Springerlink.com

\begin{abstract}
Des-aspartate-angiotensin I (DAA-I) is an endogenous angiotensin peptide and a prototype angiotensin receptor agonist (ARA). It acts on the angiotensin $\mathrm{AT}_{1}$ receptor and antagonises the deleterious actions of angiotensin II. DAA-I attenuates animal models of human disease in which angiotensin II has been implicated, such as cardiac hypertrophy, neointima formation, arteriosclerosis, renal failure, post-infarction injuries, diabetes, viral infection, chemical-induced inflammation, heat stroke, cancer, and gamma radiation lethality. DAA-I crosses Caco-2 cells and is effective at sub-nanomolar concentrations. These two properties are responsible for its oral efficacy. A single dose-escalation study was conducted to evaluate the safety, tolerability and pharmacokinetics of orally administered DAA-I in 18 healthy subjects. DAA-I was safe and well tolerated by the subjects, who were
\end{abstract}

Meng-Kwoon Sim

simmk@alumni.nus.edu.sg

1 Department of Medicine, National University of Singapore, 1E Kent Ridge Road, NUHS Tower Block Level 10, Singapore 119228, Singapore

2 Laboratory of Clinical Pharmacology, Division of Medical Sciences, Humphrey Oei Institute of Cancer Research, National Cancer Centre, Singapore, Singapore

3 Clinical Pharmacology Core, Sing Health, Singapore, Singapore

4 Office of Clinical Sciences, Duke-NUS Graduate Medical School Singapore, Singapore, Singapore

5 Biostatistics Unit, Yong Loo Lin School of Medicine, National University Health System, 1E Kent Ridge Road, NUHS Tower Block Level 11, Singapore 119228, Singapore

6 Department of Pharmacology, Yong Loo Lin School of Medicine, Block MD 3 Level 4 \#04-01, 16 Medical Drive, Singapore 117600 , Singapore administered either $0.08,0.70$ or $1.50 \mathrm{mg} / \mathrm{kg}$ of the compound. The heart rate and systolic and diastolic blood pressures determined at each post-dose measurement remained within the clinically acceptable range. Across all cohorts, DAA-I had no substantial effect on blood pressures compared with placebo. Electrocardiographs (ECGs) were normal, and none of the subjects complained of chest discomfort. All clinical laboratory tests obtained before and after DAA-I and placebo treatment were normal. Pharmacokinetic analysis over a 12 -h period following DAA-I administration did not show any increase of its level beyond basal concentration. This is in line with studies showing that intravenously administered DAA-I is rapidly metabolized and has a short half-life. We postulate that, during its short systemic sojourn, DAA-I exerts its actions via biased agonism on the angiotensin $\mathrm{AT}_{1}$ receptor.

The ClinicalTrial.gov assignment number for this study is NCT02666196. 


\section{Key Points}

The safety, tolerability, and pharmacokinetics of desaspartate-angiotensin I (DAA-I), an endogenous angiotensin peptide, were studied in 18 subjects (12 DAA-I treated and 6 placebo).

DAA-I was well tolerated, and all DAA-I-treated subjects did not experience untoward effects or show abnormal clinical test readings when administered with $0.08,0.7,1.5 \mathrm{mg} / \mathrm{kg}$ of the peptide.

Plasma level of DAA-I determined during the 12-h postadministration period was not significantly different from basal level, and this was due to its rapid degradation by blood enzymes, as shown in earlier preclinical studies.

Earlier studies showed that DAA-I was efficacious in seven animal models of human disease. We postulate the same efficacies for human, and that DAA-I acts as a biased agonist on the angiotensin $\mathrm{AT}_{1}$ receptor at ultra low doses prior to its degradation in the circulation.

\section{Introduction}

Des-aspartate angiotensin I (DAA-I) is a functional angiotensin peptide that acts as an agonist on the angiotensin $\mathrm{AT}_{1}$ receptor and elicits responses opposing those of angiotensin II. Accordingly, DAA-I has been shown to be efficacious in animal models of cardiac hypertrophy [1], neointima formation [2], arteriosclerosis [2], renal failure [3], post-infarction injuries [4, 5], diabetes [6, 7], viral infection [8], chemical-induced inflammation [9], heat stroke [10], cancer [10] and gamma radiation lethality [11], where it has been found to significantly attenuate the severity of the pathology. At effective doses, DAA-I has no observable effects on the basal physiological and biochemical parameters that were measured in these studies and was found to lack secondary responses that could be considered adverse or side effects. At the cellular level, DAA-I is known to exert anti-inflammatory actions [10]. Binding of DAA-I to the angiotensin $\mathrm{AT}_{1}$ receptor releases prostaglandins, which function as autocrines and/or second messengers [12]. In human umbilical vein endothelial cells, DAA-I specifically released prostaglandin $\mathrm{E}_{2}\left(\mathrm{PGE}_{2}\right)$ and $\mathrm{PGI}_{2}$ via cyclooxygenase (COX)-1 at sub-nanomolar concentrations. The release of $\mathrm{PGE}_{2}$ and $\mathrm{PGI}_{2}$ via the angiotensin $\mathrm{AT}_{1}$ receptor and $\mathrm{COX}-1$ was identified as a novel action specific to DAA-I [13], and it is likely that the beneficial effects of DAA-I are mediated by the two prostaglandins. This specific action is definable as a biased agonism of the angiotensin $\mathrm{AT}_{1}$ receptor, which identifies DAA-I as a novel biased agonist and potential therapeutic able to produce specific prostaglandins at sub-nanomolar concentrations [13].

A specific aminopeptidase has been shown to cleave aspartate from angiotensin I to form DAA-I, a nine amino acid peptide consisting of Arg-Val-Tyr-Ile-His-Pro-PheHis-Leu [14, 15]. Its level in human plasma has been estimated to be 19.5 pmole/l [16]. When infused into dogs [17] and human subjects [18], DAA-I is rapidly metabolised by blood angiotensin-converting enzyme (ACE) to angiotensin III and to angiotensin IV and smaller inactive peptide fragments by blood peptidases. However, active concentrations above the basal level are achievable with orally administered DAA-I. This is because DAA-I is active at sub-nanomolar concentrations, and these concentrations are 1000-fold lower than the $\mathrm{Km}$ of most enzymes [12]. The angiotensin $\mathrm{AT}_{1}$ receptors rapidly internalize upon ligand binding, and this is likely to result in sufficient amounts of DAA-I entering target tissues. DAA-I has been shown to cross the Caco- 2 monolayer via passive diffusion, indicating it could cross intestinal epithelial cells [19].

DAA-I constitutes a new member of the class of drugs that act by attenuating the deleterious actions of angiotensin II. The other well-known members of this class are the ACE inhibitors, which act by attenuating the formation of angiotensin II; and the angiotensin receptor blockers (ARBs), which act as receptor antagonists of angiotensin II. However, unlike ACE inhibitors and ARBs, DAA-I is a prototype angiotensin $\mathrm{AT}_{1}$ receptor agonist (ARA) [12]. The toxicological profile obtained from the preclinical studies is favourable to the study of DAA-I in human subjects. The findings from non-clinical pharmacological studies are equally predictive of its oral efficacy in human subjects. Hence, the desire to conduct a single-dose phase I clinical trial of DAA-I. The primary objective of this study was to evaluate the safety and dose range of DAA-I after administration of a single oral dose to healthy individuals. The secondary objective was to evaluate the pharmacokinetics of DAA-I after single oral dose administration. Overall, the present study is a prelude and prerequisite to a multi-dose phase I study of DAA-I.

\section{Methods}

\subsection{Regulatory Approval}

The clinical study protocol, subject information sheets, written inform consent forms and all other relevant study documents were reviewed and approved by the responsible 
Table 1 Baseline demographics and clinical characteristics of study subjects

\begin{tabular}{ll}
\hline Characteristics & \\
\hline Continuous variables, $N=18$ & $35 \pm 7(24-47)$ \\
Age (years) & $173 \pm 7(161-188)$ \\
Height $(\mathrm{cm})$ & $70 \pm 12.6(52.3-89.4)$ \\
Weight $(\mathrm{kg})$ & $23.4 \pm 2.8(19.1-30.0)$ \\
BMI $\left(\mathrm{kg} / \mathrm{m}^{2}\right)$ & $116 \pm 11(100-138)$ \\
Systolic pressure $(\mathrm{mmHg})$ & $69 \pm 9(56-87)$ \\
Diastolic pressure $(\mathrm{mmHg})$ & $85 \pm 9(73-104)$ \\
Mean arterial pressure $(\mathrm{mmHg})$ & $66 \pm 9(53-90)$ \\
Heart rate $(\mathrm{bpm})$ & \\
Categorical variables & \\
Race & $17(94)$ \\
Chinese & $1(6)$ \\
Javanese & $17(94)$ \\
Sex & $1(6)$ \\
Male & \\
Female & \\
\hline
\end{tabular}

Data are presented as mean \pm standard deviation or $n(\%)$

$B M I$ body mass index, $S D$ standard deviation

Institutional Review Board (Health Science Authority, Singapore) and Ethics Review Board (Domain Specific Review Boards, Singapore). The study was conducted under the principles set forth in the Declaration of Helsinki and the guidelines of the International Conference on Harmonization (ICH) on Good Clinical Practice (GCP) and was monitored by the Singapore Clinical Research Institute. All subjects were informed of the nature, purpose and requirements of the study, and their written informed consent was obtained prior to the pre-study screening procedures. The study was conducted at the Investigation Medicine Unit of the National University Health System, Singapore.

\subsection{Subject and Recruitment}

Healthy males and females, aged 21-50 years (inclusive), with body mass index (BMI) of $19-30 \mathrm{~kg} / \mathrm{m}^{2}$ were recruited into the study after screening. Table 1 summarizes the clinical characteristics of the study subjects.

\subsection{Study Drug}

DAA-I was synthesized by BACHEM AG, Switzerland, according to Good Manufacturing Practice (GMP) and packed as a solid compound in vials containing 7.1, 59.2 and $130.3 \mathrm{mg}$ per vial. The purity of DAA-I was $99.7 \%$ with a shelf life of 2 years when stored desiccated at $4{ }^{\circ} \mathrm{C}$. DAA-I was prepared for oral administration by dissolving the solid compound in each vial with $25 \mathrm{ml}$ of sterile water on the day of need. The correct weight-adjusted dose was made by adjusting the volume of the dissolved DAA-I given to each subject. The appropriate volume of DAA-I solution was drunk by the subject while standing, and this was followed by the subject drinking another $200 \mathrm{ml}$ of sterile water.

\subsection{Study Design}

The trial was a placebo-controlled randomized phase I study to investigate the safety and pharmacokinetics of DAA-I in 18 healthy subjects. The study was single-blind, and dose escalation was performed in a step-wise manner of up to three dose levels of DAA-I. In this sequential stepwise design, a single dose of DAA-I or placebo was administered to six subjects per treatment group. For each dose level, four subjects received DAA-I and two subjects received placebo (sterile water) in a randomized manner. There was an interval of $6 \mathrm{~h}$ between the dosing of the first and second DAA-I-treated subjects of each cohort to allow for early cardiovascular monitoring. The remaining subjects were simultaneously dosed after the investigators had established safety in the clinical monitoring following the first dose. Dose escalation to the next level was only allowed upon completion of the preceding dose level and following review of the safety results from the preceding dose level(s).

\subsection{Study Schedule}

The subjects attended a screening visit, a stay-in study period of 2 days and 2 nights and a follow-up visit at the trial site. Screening visits were conducted between day -28 to day -1 of the trial. The trial procedures performed at the screening visits included the following: (1) signing of written informed consent; (2) physical examination, medical history, measurement of weight and height; (3) assessment of vital signs (blood pressure, heart rate, pulse oximetry, body temperature and breathing rate); (4) full blood count; (5) renal function test (serum creatinine levels, albumin, blood urea nitrogen, phosphorus, potassium, sodium and glucose); (6) liver function tests (alanine aminotransferase [ALT], aspartate aminotransferase [AST], alkaline phosphatase [ALP], lactate dehydrogenase [LDH], and bilirubin); (7) urinalysis, urine pregnancy test (for females with child-bearing potential); and (8) 12-lead electrocardiogram (ECG).

Eligible subjects were admitted to the trial centre on day -1 . The subjects were sent to bed by 22:00 $\mathrm{h}$, and no food was allowed from 12 midnight onwards. Subjects were woken up at 07:00 h on day 1 . Before administration of the study drug, a brief physical examination, vital sign 
assessment and 12-lead ECG were performed. Blood was then sampled for full blood count, renal and liver function tests, urinalysis, random glucose and urine pregnancy test (if applicable) and aldosterone test. Each subject was cannulated for pharmacokinetic blood sampling. At 08:00 $\mathrm{h}$, the subjects received the assigned study drug (DAA-I or placebo), and no food intake was allowed $2 \mathrm{~h}$ following drug or placebo administration. Water intake was allowed up to a maximum of $200 \mathrm{ml}$.

Vital signs were assessed at $0.25,0.5,0.75,1,2,3,4,5$, 6, 12 and 24 h post dose, and 12-lead ECG was conducted at $1,3,6$ and $12 \mathrm{~h}$ post dose. Blood samples were collected at $24 \mathrm{~h}$ post dose for determination of full blood count, liver function tests and renal function tests. Blood glucose was measured in blood samples at 2, 3, 4, 5 and $6 \mathrm{~h}$ following drug or placebo administration, and an aldosterone test was performed at 1 and $4 \mathrm{~h}$ post dose. The subjects were discharged on day 2 and returned to the trial centre the following day for follow-up assessment.

\subsection{Pharmacokinetic Measurement}

Serial venous blood samplings $(10 \mathrm{ml})$ for pharmacokinetic analyses were carried out on all subjects at $0,0.25,0.5,1,2,3$, $4,5,6$ and $12 \mathrm{~h}$ post study drug administration. We anticipated that the range of sampling time points would cover the duration of early blood pressure response to intravenous administration of DAA-I observed in human subjects [18], and the detection of chromatographic $\left[{ }^{14}\right] \mathrm{C}-\mathrm{DAA}-\mathrm{I}$-like peak at $4 \mathrm{~h}$ after $\left[{ }^{14}\right] \mathrm{C}$-DAA-I was orally administered to rats during the preclinical toxicology studies.

Each $10 \mathrm{ml}$ of collected blood sample was immediately transferred to a centrifuge tube containing $200 \mu \mathrm{l}$ of an aqueous solution of $50 \mathrm{mM}$ EDTA and $50 \mathrm{mM}$ captopril and gently mixed to prevent the degradation of DAA-I by blood ACE and peptidases. Captopril and EDTA are inhibitors of ACE, and EDTA is an inhibitor of peptidases. Plasma was collected by immediately centrifuging the mixture at $4{ }^{\circ} \mathrm{C}$ and stored at $-20{ }^{\circ} \mathrm{C}$ for batch analysis.

The plasma samples were analysed for DAA-I concentrations using an Agilent 1290 Infinity Binary UHPLC system coupled to an Agilent 6495 triple quadrupole MS/ MS system. An Agilent Poroshell SB-C18 column $(50 \mathrm{~mm} \times 3 \mathrm{~mm}, 2.7 \mu \mathrm{m}$ particle size) was used for chromatography set at $40.0^{\circ} \mathrm{C}$. For MS detection, an ESI ion source operating in positive ion mode was used for all analyses. The Agilent Masshunter software, version B.06.00, was used for data collection. The method was validated for a concentration range of $25 \mathrm{pg} / \mathrm{ml}$ (lower limit of quantification [LLOQ]) and $1000 \mathrm{pg} / \mathrm{ml}$ (upper limit of quantification [ULOQ]) according to ICH guidelines on accuracy, precision (repeatability), linearity, range (recovery), and specificity.

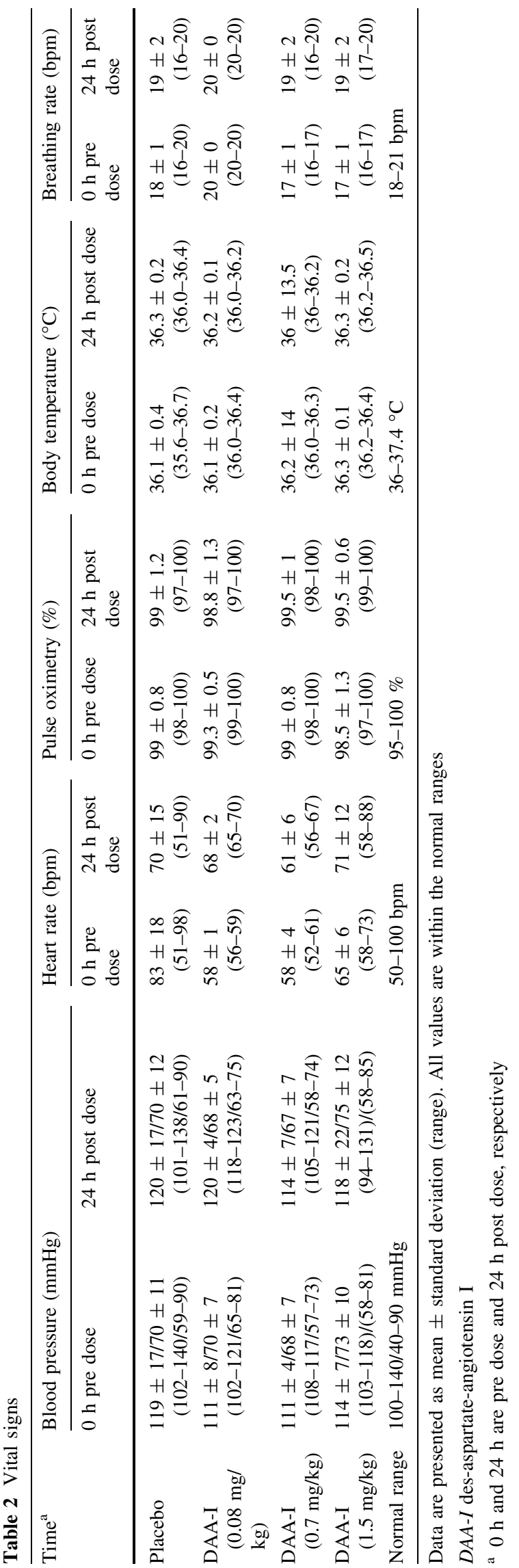


Table 3 Blood aldosterone level

\begin{tabular}{llll}
\hline Time & $0 \mathrm{~h}$ pre dose & $1 \mathrm{~h}$ post dose & $4 \mathrm{~h}$ post dose \\
\hline Placebo & $340 \pm 121(196-511)$ & $206 \pm 112(112-345)$ & $280 \pm 103(390-95)$ \\
DAA-I $(0.08 \mathrm{mg} / \mathrm{kg})$ & $261 \pm 95(160-354)$ & $167 \pm 66(87-241)$ & $239 \pm 145(113-461)$ \\
DAA-I $(0.7 \mathrm{mg} / \mathrm{kg})$ & $351 \pm 178(185-597)$ & $179 \pm 64(110-236)$ & $166 \pm 66(103-248)$ \\
DAA-I $(1.5 \mathrm{mg} / \mathrm{kg})$ & $340 \pm 197(86-512)$ & $199 \pm 62(108-244)$ & $213 \pm 60(135-282)$ \\
\hline
\end{tabular}

Data are presented as mean \pm standard deviation (range). All values are within the normal range of $<445 \mathrm{pmol} / 1$

$D A A-I$ des-aspartate-angiotensin I

\subsection{Statistical Analysis and Analysis of Measured Clinical Parameters}

We employed analysis of variance (ANOVA) to test for significant difference between the grouped area under the plasma concentration-time curve (AUC) of the 12 subjects who were administered DAA-I and the grouped AUC of the six subjects who were administered placebo. A $p<0.05$ indicates significance. The normal range of values of the College of American Pathologists checklist was used to categorise all laboratory tests.

\section{Results}

A total of 18 healthy subjects (17 males and 1 female) aged 24-47 years enrolled and participated in this study (Table 1). All subjects, except one, were Chinese, which reflects the predominantly Chinese demographics of Singapore. No subjects withdrew, and all 18 subjects complied with the trial procedures and completed the study.

\subsection{Safety and Tolerability}

DAA-I was safe and well tolerated by the subjects. No adverse event was observed in the subjects who were administered either $0.08,0.70$ or $1.50 \mathrm{mg} / \mathrm{kg}$ of DAA-I. The vital signs (heart rate, systolic and diastolic blood pressure, pulse oximetry, body temperature and breathing rate) determined at each post-dose measurement remained within the clinically acceptable range. Table 2 shows the values of the vital signs obtained at $0 \mathrm{~h}$ (pre-dose) and $24 \mathrm{~h}$ post dose. Across all cohorts, DAA-I had no substantial effect on blood pressures compared with placebo. ECGs were normal, and none of the subjects complained of chest discomfort. The level of aldosterone in the plasma of the 18 subjects obtained before DAA-I or placebo administration and at 1 and $4 \mathrm{~h}$ post-administration were within the normal range (Table 3). All other clinical laboratory tests obtained before and after DAA-I and placebo treatment were normal. The results of the liver function test, renal function test and urinalysis carried out at $0 \mathrm{~h}$ (pre-dose) and $24 \mathrm{~h}$ post dose are displayed in Tables 4, 5 and 6, respectively.

\subsection{Pharmacokinetics}

The concentration of DAA-I in the ten plasma samples obtained from each subject was determined and plotted against the sampling time to obtain the AUC. Figure 1 displays the mean AUC of the four DAA-I-treated and two placebo-treated subjects in each of the three subject cohorts. Subjects who were administered DAA-I did not show any specific DAA-I plasma profile that differed from the corresponding profile of the placebo subjects. The value of each AUC was determined by the trapezoid method and is displayed in Table 7. The AUC of the DAA-I-treated subjects was compared with that of the placebo-treated subjects by one-way ANOVA for statistical difference. There was no significant difference in the AUC between the two groups for the three doses of DAA-I.

\section{Discussion}

Kono et al. [18] demonstrated that increases in blood pressure and plasma aldosterone were the immediate responses to an intravenous infusion of DAA-I in human subjects. Hence, data obtained from blood pressure and ECG monitoring and plasma aldosterone determination conducted in this study would provide indications of adverse responses arising from the oral administration of DAA-I. The data obtained from subjects who received either one of the three oral doses of DAA-I $(0.08,0.7$ and $1.5 \mathrm{mg} / \mathrm{kg}$ ) were either within normal ranges or absent of any abnormal pattern. The oral dose of $1.5 \mathrm{mg} / \mathrm{kg}$ is more than two times the maximum effective hypoglycaemic dose of DAA-I $(0.71 \mathrm{mg} / \mathrm{kg}$ or $600 \mathrm{nmole} / \mathrm{kg})$ that has been shown to attenuate insulin resistance $[6,7]$ and mediators of chronic inflammation in animal models of type 2 diabetes [7]. These show that DAA-I is safe and well tolerated in human subjects and could be administered at the anticipated anti-diabetic dose of $0.71 \mathrm{mg} / \mathrm{kg}$ to patients with diabetes. This premise is supported by data from an earlier 

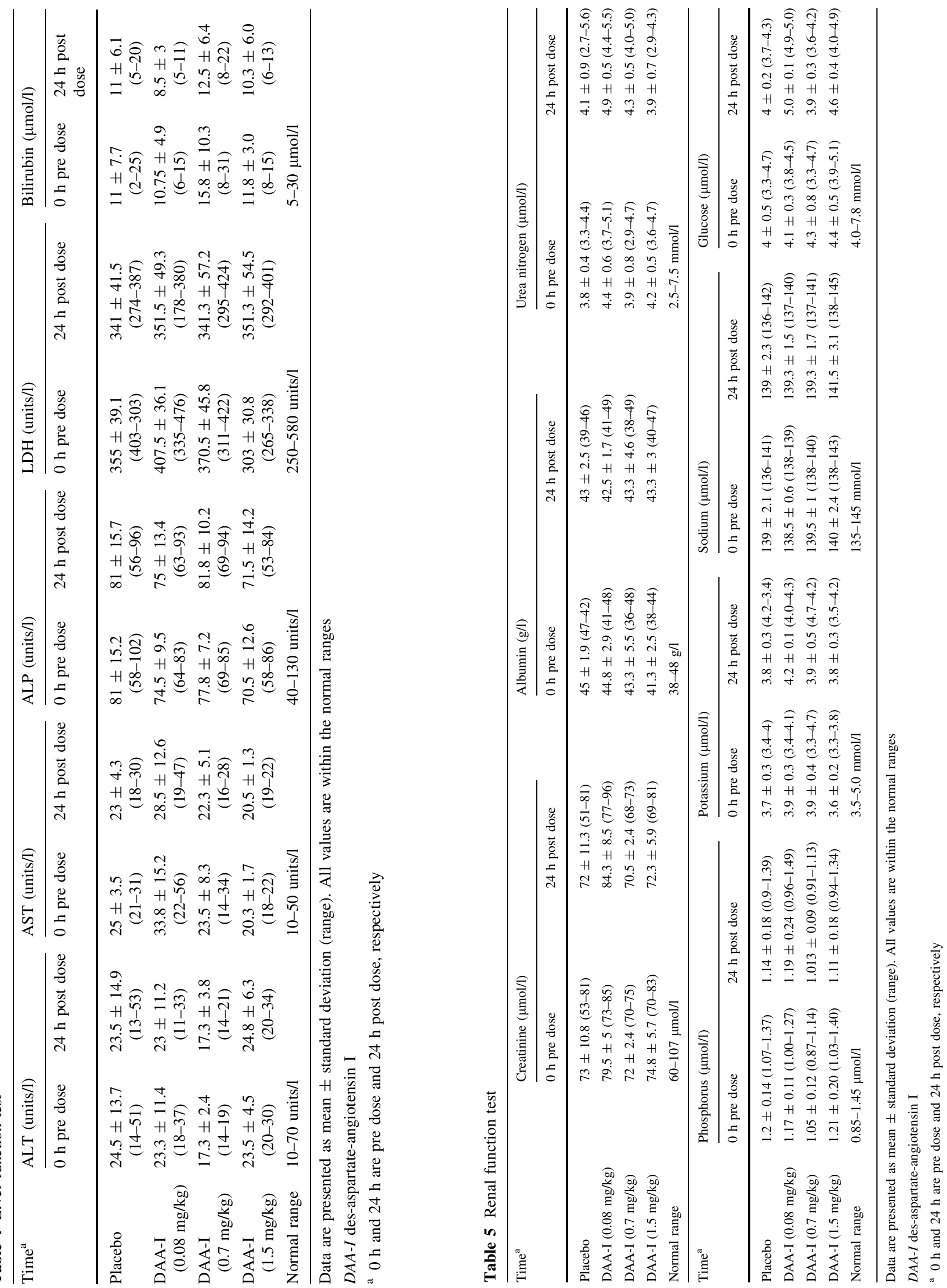


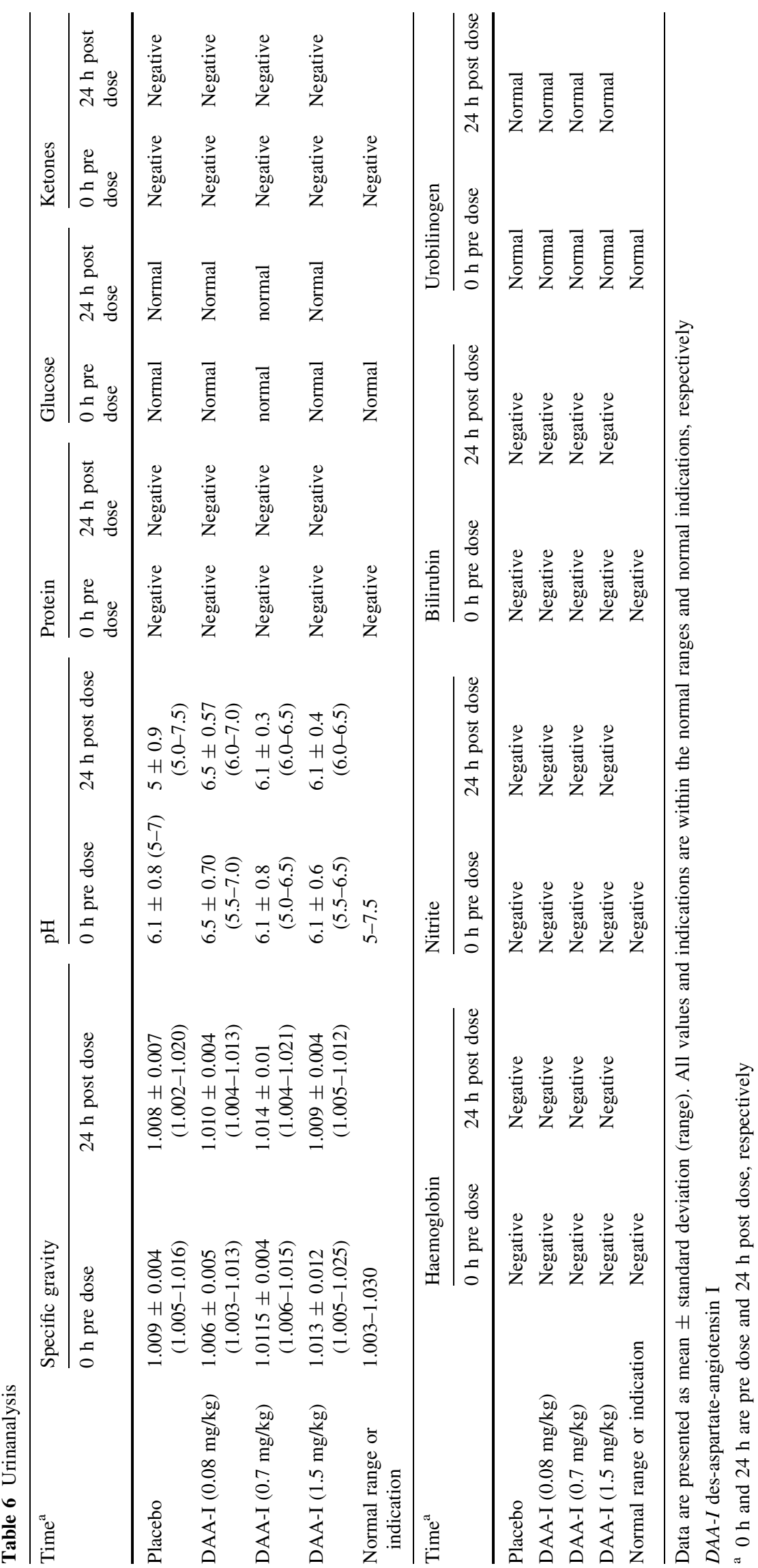



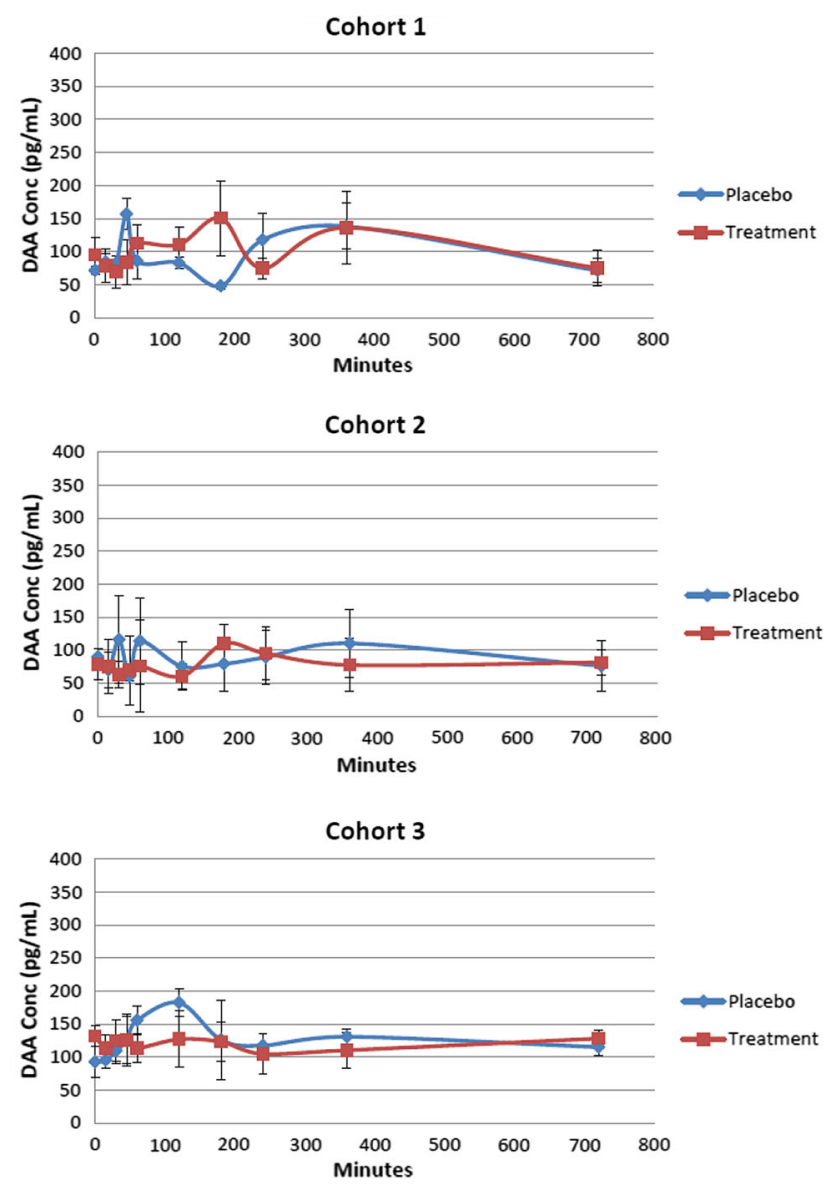

Fig. 1 Plot of averaged plasma DAA-I concentration vs. sampling time. Top panel plot of cohort 1 subjects who received either $0.08 \mathrm{mg} / \mathrm{kg}$ DAA-I (four subjects) or placebo (two subjects). Middle panel plot of cohort 2 subjects who received either $0.70 \mathrm{mg} / \mathrm{kg}$ DAAI (four subjects) or placebo (two subjects). Bottom panel plot of cohort 3 subjects who received either $1.5 \mathrm{mg} / \mathrm{kg}$ DAA-I (four subjects) or placebo (two subjects) preclinical study showing that the heart rate and blood pressure (tracked by telemetry monitoring) of conscious freely moving rats were not affected by a single oral dose of DAA-I given as 5, 10, and $20 \mu$ mole $/ \mathrm{kg}(5.9,11.8$ and $23.6 \mathrm{mg} / \mathrm{kg}$ ) (unpublished preclinical toxicological data).

When intravenously administered into rats, DAA-I is rapidly degraded by plasma enzymes within $2-5$ min (unpublished preclinical toxicological data). Other investigators have reported similar short durations in systemic circulation following an intravenous administration of the compound in dogs [17] and human subjects [18]. The present study shows there was no increase in circulating DAA-I in subjects who received oral DAA-I at doses shown to be effective in attenuating animal models of human disease. Although this observation seems to be a discrepancy, it is not unexpected, as the rapid metabolism of absorbed DAA-I by blood enzymes would again result in a short systemic sojourn, the duration of which could be shorter than the blood sampling time of 2-3 min and the blood sampling interval of $15 \mathrm{~min}$. Despite its rapid degradation and short systemic sojourn, DAA-I is effective in combating animal models of human disease when administered either intravenously or orally [12]. Two major mechanisms are likely involved. First, in certain in situ preparations where the circulating blood was replaced with physiological solution, DAA-I was effective at ultra-low concentrations that are below the Km of enzymes. At femto $\left(10^{-15}\right)$ molar concentration, DAA-I has been shown to attenuate the pressor actions of angiotensin III in the renal and mesenteric vasculature of the spontaneously hypertensive rat [20], and at atto $\left(10^{-18}\right)$ molar concentration, to attenuate the pressor actions of angiotensin II in similar vascular beds of the normo- and hypertensive rats [21]. Being effective at concentrations lower than the $\mathrm{Km}$ of
Table 7 Area under the plasma concentration versus time curve of placebo and DAA-I-treated subjects (AUC)

\begin{tabular}{ccccllll}
\hline Dose level & \multicolumn{7}{l}{ AUC $(\mathrm{pg} 12 \mathrm{~h} / \mathrm{ml})$} \\
\cline { 2 - 8 } & Subject 1 & Subject 2 & Subject 3 & Subject 4 & Subject 5 & Subject 6 & Mean \pm SD \\
\hline Level 1 $(0.08 \mathrm{mg} / \mathrm{kg})$ & & & & & & \\
Placebo & 85,595 & 64,390 & - & - & - & - & $74,993 \pm 14,994$ \\
DAA-I & - & - & 15,2282 & 50,802 & 58,768 & 54,301 & $79,038 \pm 48,938$ \\
Level 2 $(0.70 \mathrm{mg} / \mathrm{kg})$ & & & & & & \\
Placebo & 75,724 & 56,454 & - & - & - & - & $66,089 \pm 13,626$ \\
DAA-I & - & - & 48,953 & 45,813 & 65,180 & 73,266 & $58,303 \pm 13,097$ \\
Level 3 $(1.50 \mathrm{mg} / \mathrm{kg})$ & & & & & & \\
Placebo & 89,986 & 95,223 & - & - & - & - & $92,605 \pm 3703$ \\
DAA-I & - & - & 81,675 & 76,230 & 92,276 & 88,237 & $84,605 \pm 7089$ \\
\hline
\end{tabular}

Blood was sampled before oral administration of DAA-I or placebo and at $0.25,0.50,1,2,3,4,5,6$ and $12 \mathrm{~h}$ after administration. The AUC measures the amount of DAA-I in systemic circulation during the $12 \mathrm{~h}$ following administration. There was no significant difference between the grouped AUC of the 12 subjects who received DAA-I and the grouped AUC of the six subjects who received placebo $(p=0.764$, ANOVA) $A N O V A$ analysis of variance, $A U C$ area under the plasma concentration-time curve, DAA-I des-aspartateangiotensin I, $S D$ standard deviation 
enzymes (the $\mathrm{Km}$ of most enzymes is $10^{-6} \mathrm{M}$ ), our earlier studies have shown that substantial effective concentrations of DAA-I could be attained either by the intravenous or oral route of administration [12]. In a study where both intravenous and oral DAA-I were shown to produce similar magnitudes of attenuation of cardiac hypertrophy, an oral bioavailability of 0.06 was shown to account for its anticardiac hypertrophy action [12]. DAA-I has been shown to cross the Caco-2 monolayer via passive diffusion [19], indicating it would cross intestinal epithelial cells. The second mechanism is the rapid internalization (within minutes) of the G-protein-coupled receptor (which includes the angiotensin $\mathrm{AT}_{1}$ receptor) upon ligand binding $[22,23]$. Pharmacodynamic and efficacy studies show that DAA-I exerts its action by acting as an agonist on the angiotensin $\mathrm{AT}_{1}$ receptor [12]. Upon the binding of DAA-I to the $\mathrm{AT}_{1}$ receptor, the receptor internalizes and the DAA-I/receptor complex has been shown to remain active and to specifically release $\mathrm{PGE}_{2}$ and $\mathrm{PGI}_{2}$ [13]. Glucagon-like peptide (GLP)-1, which binds to the GLP-1 receptor (another G-protein-coupled receptor) and internalizes [24], has also been shown to be active after its blood level has returned to circulating levels following cessation of administration via osmotic pump [25]. Like DAA-I, GLP-1 is rapidly metabolized in the circulation and has a half-life of 1.5-5 minutes [25]. DAA-I has been shown to be a biased agonist of the angiotensin $\mathrm{AT}_{1}$ receptor [13], and a recent study by Szakadáti et al. [26] shows that internalization of the angiotensin $\mathrm{AT}_{1}$ receptor is accelerated upon binding by a biased agonist. This accelerated internalization would also rapidly remove absorbed DAA-I from the circulation and contribute to its short systemic sojourn, while simultaneously ensuring that DAA-I reaches its target. To confirm that oral DAA-I enters the systemic circulation in effective amounts and reaches its target, we anticipate a 2-week multi-dose phase I study of DAA-I that focuses on measuring $\mathrm{PGE}_{2}$ and $\mathrm{PGI}_{2}$ as surrogate biomarkers of DAA-I. This multi-dose study would hold much promise, as chronic oral administration of DAA-I $800 \mathrm{nmole} / \mathrm{kg} /$ day $(0.95 \mathrm{mg} / \mathrm{kg} / \mathrm{day})$ to mice has been shown to cause a significant rise in plasma $\mathrm{PGE}_{2}$ in the animals after 2 weeks of oral administration [11].

\section{Conclusion}

This study indicates oral DAA-I is safe and well-tolerated when administered up to a dose of $1.5 \mathrm{mg} / \mathrm{kg}$. This dose is more than twice the anticipated anti-diabetic dose of $0.71 \mathrm{mg} / \mathrm{kg}$. In terms of safety and tolerability limits, preclinical data indicate DAA-I has a very much higher potential limit: a preclinical toxicological study showed an oral dose of $23.6 \mathrm{mg} / \mathrm{kg}$ to rats had no effect on the blood pressure and heart of the animals. The absence of a pharmacokinetic profile after a single oral administration of DAA-I in human subjects supports the known short sojourn of DAA-I in the systemic circulation. This puts DAA-I in a very special class of drugs that are active at ultra-low concentrations (below the $\mathrm{Km}$ of enzymes) and remain active after the systemic concentration has reverted to basal level. The internalization of the angiotensin $\mathrm{AT}_{1}$ receptor upon DAA-I binding and the following biased agonism that results in the release of $\mathrm{PGE}_{2}$ and $\mathrm{PGI}_{2}$ via a specific COX1 pathway [13] indicate that DAA-I holds great promise as a very specific drug.

\section{Compliance with Ethical Standards}

Funding The study was supported by Grant R-184-000-237-511 from the National Medical Research Council, Singapore.

Conflict of interest All the authors have no conflicts of interest with regard to financial sponsorship or governmental guidelines on the publication of this manuscript.

Open Access This article is distributed under the terms of the Creative Commons Attribution-NonCommercial 4.0 International License (http://creativecommons.org/licenses/by-nc/4.0/), which permits any noncommercial use, distribution, and reproduction in any medium, provided you give appropriate credit to the original author(s) and the source, provide a link to the Creative Commons license, and indicate if changes were made.

\section{References}

1. Sim MK, Min L. Effects of des-Asp-angiotensin I on experimentally-induced cardiac hypertrophy in rats. Int $\mathrm{J}$ Cardiol. 1998;63:223-7.

2. Sim MK, Tang FR, Xu XG. Effects of des-aspartate-angiotensin I on neointima growth and cardiovascular hypertrophy. Regul Pept. 2004;117:213-7.

3. Sim MK, Tan CC. Use of des-aspartate-angiotensin I as an agent for the treatment and prevention of glomerulosclerosis and renal failure. United States Patent No. US7553,928, B2, Jun 20, 2009.

4. Wen Q, Sim MK, Tang FR. Reduction of infarct size by orally administered des-aspartate-angiotensin I in the ischemic reperfused rat heart. Regul Pept. 2004;120:149-53.

5. Wen Q, Sim MK. Effects of des-aspartate-angiotensin I on myocardial ischemia-reperfusion injury in rats. Eur J Pharmacol. 2011;658:193-9.

6. Sim MK, Xu XG, Wong YC, Sim SZ, Lee KO. Des-aspartateangiotensin I exerts hypoglycemic action via glucose transporter4 translocation in type 2 diabetic KKAy mice and GK rats. Endocrinology. 2007;148:5925-32.

7. Wong WC, Sim MK, Lee KO. Des-aspartate-angiotensin-I and angiotensin IV improve glucose tolerance and insulin signalling in diet-induced hyperglycaemic mice. Biochem Pharmacol. 2011;82:1198-208.

8. Sim MK. Use of des-aspartate-angiotensin I. United States Patent, Pub No. US 2008/0249015A1, Oct 9, 2008.

9. Ng ET, Sim MK, Loke WK. Protective actions of des-aspartateangiotensin I in mice model of CEES-induced lung intoxication. J Appl Toxicol. 2011;31:568-78. 
10. Sim MK. The use of des-aspartate-angiotensin I in inflammationrelated pathologies and diseases. Patent Cooperation Treaty, International Application No. PCT/SG2011/000204, 08 Jun 2011.

11. Wang H, Sethi G, Loke WK, Sim MK. Des-aspartate-angiotensin I attenuates mortality of mice exposed to gamma radiation via a novel mechanism of action. PLoS One. 2015;. doi:10.1371/ journal.pone.0138009.

12. Sim MK. Des-aspartate-angiotensin $\mathrm{I}$, a novel angiotensin $\mathrm{AT}_{1}$ receptor drug. Eur J Pharmacol. 2015;760:36-41.

13. Wen Q, Lee KO, Sim SZ, Xu XG, Sim MK. Des-aspartate-angiotensin I causes specific release of $\mathrm{PGE}_{2}$ and $\mathrm{PGI}_{2}$ in HUVEC via the angiotensin $\mathrm{AT}_{1}$ receptor and biased agonism. Eur $\mathrm{J}$ Pharmacol. 2015;768:173-81.

14. Sim MK. Degradation of angiotensin I in the endothelium and smooth muscle of the rat aorta. Biochem Pharmacol. 1993;45:1524-7.

15. Sim MK, Choo HM, Qiu XS. Degradation of angiotensin I to [des-Asp1]angiotensin I by a novel aminopeptidase in the rat hypothalamus. Biochem Pharmacol. 1994;48:1043-6.

16. Sim MK, Qui XS. Angiotensins in plasma of hypertensive rats and human. Regul Pept. 2003; 111:179-82.

17. Gayes RP, Szidon JP, Opari S. In vivo and in vitro conversion of des-1-Asp angiotensin I to angiotensin III. BiochemPharmacol. 1978;27:2871-7.

18. Kono T, Ikeda F, Oseko F, Imura H. Endo J. Biological activity of des-asp ${ }^{1}$-angiotensin $\mathrm{I}$ in man. J Clin Endocrinol Metab. 1980;50:40-5.
19. Chua HL, Jois S, Sim MK, Go ML. Transport of angiotensin peptides across the Caco-2 monolayer. Peptides. 2004;25:1327-38.

20. Mustafa MR, Dharmani M, Kunheen NK, Sim MK. Effects of des-aspartate-angiotensin I on the angiotensin III in the renal and mesenteric vasculature of normo- and hypertensive rats. Regul Pept. 2004;120:15-22.

21. Dharmani M, Mustafa MR, Achike FI, Sim MK. Effect of desaspartate-angiotensin on the angiotensin II in the isolated renal and mesenteric vasculature of hypertensive and STZ-induced diabetic rats. Regul Pept. 2005;129:213-9.

22. Drake MT, Shenoy SK, Lefkowitz RJ. Trafficking of G proteincoupled receptors. Circ Res. 2006;99:570-82.

23. Calebiro D, Nikolaev VO, Persani L, Lohse MJ. Signaling by internalize G-protein-coupled receptors. Trends Pharmacol Sci. 2010;31:221-8.

24. Roed SN, Wismann P, Underwood CR, et al. Real-time trafficking and signaling of the glucagon-like peptide-1 receptor. Mol Cell Endocrinol. 2014;382:938-49.

25. Hui H, Farilla L, Merkel P, Perfetti R. The short half-life of glucagon-like peptide-1 in plasma does not reflect its long-lasting beneficial effects. Eur J Endocrinol. 2002;146:863-9.

26. Szakadáti G, Tóth $\mathrm{AD}$, Oláh I, et al. Investigation of the fate of type I angiotensin receptor after biased activation. Mol Pharmacol. 2015;87:972-81. 